\title{
A questão da escala no ensino de climatologia no ensino Fundamental e Médio em Curitiba e região metropolitana
}

\section{The issue of scale in climatology education at elementary and high school in Curitiba and metropolitan region}

Francisco Jablinski Castelhano * Wilson Flavio Feltrim Roseghini **

\section{Resumo:}

Este artigo trabalha com o conceito de escala no ensino de geografia em particular na área de climatologia. Se aproveitando de conceitos propostos por Piaget (1996), Carvalho (2006) e Tuan (1975) os autores visam identificar qual a escala adequada para se tratar os fenômenos climatológicos dentro de sala de aula, analisando livros didáticos para entender como os mesmos abordam esta ciência. Após tal discussão teórica, foi realizado um levantamento com uma amostra de professores dos ensinos fundamental e médio de Curitiba e Região Metro-politana a fim de se entender como de fato se da o ensino de climatologia em sala de aula, e também a relação de dependência entre o professor e o livro didático, visto que a abordagem do segundo se mostrou muito generalista. Ao fim da pesquisa, observou-se que a escolha da escala de estudo, na grande maioria dos casos é pessoal do professor, tendo em vista que den-tre os entrevistados, somente 6,38\% alegaram não ter liberdade para tratar de assuntos fora do livro e outros $6,38 \%$ não ter liberdade para se aprofundar em assuntos do livro.

\begin{abstract}
:
This article focuses on the concept of scale at the geography education in particular at the cli-matology area. Using concepts proposed by Piaget (1996), Carvalho (2006) and Tuan (1975), the authors aim to identify the appropriate scale for treatment of climatological phenomens in the classroom, analyzing textbooks to understand how they abord such science. After this theoretical discussion, a survey of teachers from elementary and high school from Curitiba and its metropolitan area was conducted in order to understand how in fact the climatology is the teaching at the classroom, and also the relationship between the teacher and the textbook, since the second approach proved to be very general. At the end of the research, it was ob-served that in the greater part of the cases, the choice of in which scale to work, it ends to be a personal choice of the teacher, due that only $6,38 \%$ claimed that not have freedom to work with subjects beyond the official material, and also 6,38 claimed that not have the freedom to get deeper in the books subjects.
\end{abstract}

\begin{abstract}
* Licenciado em Geografia pela Universidade Federal do Paraná (UFPR). Mestrando em Geografia no Programa de Pós-Graduação em Geografia da UFPR.

* Doutor em Geografia pela UFPR. Professor adjunto do Departamento de Geografia da UFPR.
\end{abstract}

Palavras-chave:

ensino de Geografia, climatologia, escala

Key-Words:

Geography teaching, climatology, scale 
INTRODUÇÃO

geografia dentro do ambiente escolar apaArece como uma disciplina de vital importância para o desenvolvimento de plenas capacidades sócio espaciais do aluno. Seu caráter prático e de fácil aplicabilidade à realidade dos que a estudam cooperam para a dinâmica entre aluno e professor e facilitam a compreensão de sua importância neste cenário.

Rua (1993) cita a dicotomia da geografia contemporânea e sua problemática na compreensão do espaço e da sociedade pelo aluno do ensino básico, apontando o estudo da natureza como um dos pilares da geografia escolar.

Assim, o autor menciona quatro diretrizes básicas para o ensino de geografia: Estudar a natureza de maneira totalitária e não compartimentada; Estudar o espaço geográfico, como fruto das relações sociais ao longo da historia, contendo a natureza; a compreensão da dinâmica da sociedade e da dinâmica da natureza e suas relações; e a construção de criticas da ação do homem sobre a natureza com os alunos mostrando como se dá essa relação.

O ensino da climatologia, como parte da ciência geográfica, se dá ao longo dos $6^{\circ}$ e $7^{\circ}$ ano do Ensino Fundamental, segundo os Parâmetros Curriculares Nacionais (PCN). Todavia, sabe-se que possuem um caráter muito teórico e quase nada pratico. Muitas vezes seu ensino se limita a meras espacializações de tipos de clima, através da classificação de Koppen.

A discussão a ser feita no presente trabalho tratará de como a climatologia esta sendo abordada no âmbito escolar e buscará novas abordagens através do conceito de raciocínio escalar proposto por Carvalho (2006).

Segundo Piaget (1996) a assimilação é uma etapa fundamental para o processo cognitivo. Segundo o autor, esta é a maneira como um novo dado perceptual ou um conceito é integrado à estrutura cognitiva que o aluno já possui. Tal estrutura provém da realidade vivida pelo aluno e esta deve ser abordada pelo professor.

Trazer o aprendizado para a realidade do aluno é fundamental para garantir a assimilação do mesmo, e a geografia, enquanto disciplina escolar se sobressai as demais por apresentar certa facilidade nesta aproximação no que diz respeito aos seus temas físico-ambientais.

A possibilidade de aulas não convencionais den- tro da geografia é mais do que uma realidade senão uma necessidade. Enquanto não convencionais, citamos, utilização de cartas, imagens de satélite, saídas a campo demonstrações de processos entre outros.

Todavia a mera utilização destes instrumentos não trará quaisquer mudanças no aprendizado da geografia a não ser que abordem a realidade do aluno. Neste ponto entramos na necessidade de se trabalhar o conceito de lugar dentro do ensino de geografia. Tal conceito amplamente discutido, e diferente de autor para autor é apresentado por Tuan (apud HOLZER, 1999, p.70).

[...] o lugar é uma unidade entre outras unidades ligadas pela rede de circulação; [...] o lugar, no entanto, tem mais substância do que nos sugere a palavra localização: ele é uma entidade única, um conjunto 'especial', que tem história e significado. O lugar encarna as experiências e aspirações das pessoas. O lugar não é só um fato a ser explicado na ampla estrutura do espaço, ele é a realidade a ser esclarecida e compreendida sob a perspectiva das pessoas que lhe dão significado.

A abordagem do lugar no ensino da geografia facilita a assimilação do conhecimento pelo aluno. Utilizar os instrumentos não convencionais citados acima, aplicados ao lugar onde vivem os alunos, podendo ser, o entorno da escola, o bairro, quiçá o município é fundamental.

E aqui encontramos um grande problema do ensino da geografia e especificamente da climatologia que será tratado neste artigo. Como trazer o ensino de climatologia para o lugar onde vivem os alunos?

\section{JUSTIFICATIVA}

A contemporaneidade e polêmica envolvendo questões climáticas faz de sua compreensão e aprendizado um ato necessário e fundamental para aqueles que estão em idade escolar.

A existência de um hiato no ensino de climatologia comprovado pela maneira como os livros didáticos abordam tal tema faz cair à responsabilidade pelo processo de aprendizagem pleno de tal ciência nos ombros do professor, já que, o mesmo não conta com o livro como base ou suporte para tal feito.

Desta maneira, vê-se necessário o desenvolvimento de novas abordagens neste processo, facilitando à dinâmica ensino-aprendizado, tanto no ensino fundamental quanto no médio, garantindo um mínimo de qualidade em tal situação e que os 
alunos possam sair de sala de aula compreendendo as bases da climatologia e tendo capacidade para assimilar tais conhecimentos com sua vida cotidiana.

A falta de recursos das escolas da rede pública limita a assimilação do conteúdo a qualidade do professor. Se em um ambiente onde os recursos são fartos, o professor pode contar com uma gama de ferramentas para auxiliá-lo no ensino tais como filmes, internet, e afins, um ambiente com recursos escassos, como é o caso da rede pública de ensino o professor não possui tais ferramentas, aumentando sua dependência ao livro didático.

\section{HIPOTESES}

O processo de ensino possui inúmeras dificuldades para ser concretizado, tanto do ponto de vista do professor quanto do aluno. A distância entre o aluno e sua realidade e o objeto de estudo sempre foi marcante e surge como uma das principais barreiras para o ensino/aprendizado. $O$ que se observa em especifico em assuntos da climatologia, é de uma maneira generalizada, uma não compreensão dos processos básicos desta ciência por parte dos alunos.

A escala com o qual o professor aborda as questões levantadas acaba tendo um papel primordial para garantir a facilidade deste processo, uma vez que, a assimilação de conhecimento é uma dinâmica que é facilitada quando a escala de ensino é reduzida para a realidade do estudante.

A geografia, como ciência que estuda a relação homem/natureza apresenta uma gama de opções que facilitam tal caso. Aulas de campo, demonstrações em sala de aula, entre outros, são muitos aspectos utilizados por professores da área como uma tentativa de reduzir a questão de ensino. Além do mais, é função da geografia enquanto disciplina escolar, desenvolver o chamado raciocínio escalar entre seus alunos (CARVALHO e FILIZOLA, 2006).

Aproximar o ensino do conceito de "lugar"trabaIhado neste projeto seria uma forma de diminuir esta barreira, contudo tal aspecto não vem sendo tratado no ensino da climatologia em especifico. Os conteúdos observados em livro didático apontam tal realidade.

Desta forma, reduzindo a escala de ensino para o que chamamos de "local" ou mesmo para o "lugar" seria uma forma de facilitar a compreensão de conteúdos por parte dos alunos.

\section{OBJETIVOS GERAIS}

A ideia central deste estudo é analisar qual a escala utilizada por professores de geografia do ensino médio e fundamental em especifico no âmbito da climatologia em Curitiba e na Região Metropolitana.

Baseando-se em 1- discussões e questionários, visando compreender a dinâmica atual do ensino de clima, identificar seus problemas, e propor novas abordagens que possam vir a facilitar o aprendizado, 2- e comprovar a hipótese de que a redução da escala abordada nos temas de clima facilitaria tal processo.

\subsection{Objetivos secundários}

- Analisar o material produzido por alguns dos principais materiais didáticos utilizados na área de estudo, acerca da climatologia.

- Comparar o que de fato é passado em classe pelos professores com o proposto pelo livro.

- Observar o quão livre os professores são para definir as prioridades de estudo na área de climatologia.

\section{METODOLOGIA}

Em um primeiro momento foi realizada uma análise do conteúdo de cinco livros didáticos da rede pública de ensino do estado do Paraná, onde se observou que a escala estadual era a mais abordada dentro da climatologia escolar, ainda se notou que em alguns livros, alguns aspectos climáticos gerais dos estados eram tratados, todavia aspectos mais locais eram deixados de lado.

Assim foram analisados livros didáticos de $6^{\circ}$ e $7^{\circ}$ ano para se observar como a climatologia vem sendo tratada. Os conteúdos de $6^{\circ}$ ano abordam de maneira mais direta a temática do clima. Assim, foram analisados os livros "Geografia Homem e Espaço" de Lucci e Branco, da editora Saraiva de 2010, e "Geografia espaço e vivência $6^{\circ}$ ano" da editora Atual.

Em relação ao sétimo ano, foram analisados os livros "Geografias do Mundo" de Marcos e Diamantino da Editora FTD de 2009, "Projeto Araribá" da Editora Moderna de 2007 e "Geografia, Espaço e Vivência 7º ano" da Editora Atual de 2009.

Tendo esta analise como base e levando em consideração discussões ocorridas no eixo "Ensino de climatologia" do XI Simpósio Brasileiro de Climatologia 
Geográfica ocorrido em outubro de 2014, pensou-se em um pequeno questionário que visasse esclarecer alguns pontos levantados ao longo da apresentação de trabalhos no dito tema e que englobassem os objetivos deste trabalho.

Ao longo do debate entre professores, alunos e pesquisadores do tema chegou-se a uma questão chave no que diz respeito à escala a qual o ensino é aplicado aos alunos. Tal problemática já foi abordada na climatologia por Castelhano (2014) neste mesmo simpósio, e diz respeito a quão próximo da realidade do aluno o tema tratado está inserido.

A fim de se compreender melhor a relação professor/livro didático e mesmo de fato se analisar a questão da escala no âmbito do ensino da climatologia em especifico foi elaborado um questionário contendo cinco questões que tentam trazer a realidade vivida pelos professores para este debate.

Este questionário foi feito com professores da disciplina de geografia que trabalham tanto na rede pública quanto privada em Curitiba e Região Metropolitana, de modo que possa ser alcançado certo universo de profissionais e a realidade dos mesmos possa ser mais bem retratada.

A confecção do questionário foi feita baseandose na proposta de Aaker et al. (2001), o qual propõe uma série de questões a serem levadas em conta no momento de se formular um questionário com fins científicos.

Optou-se por perguntas dicotômicas e de múltipla escolha, portanto não foram realizadas quaisquer tipo de perguntas abertas aos entrevistados. Mattar (1994) aponta que as perguntas dicotômicas têm como principal vantagem sua objetividade e agilidade na resposta e um menor risco de imparcialidade do entrevistado, todavia o autor aponta que se o tema tratado não couber entre uma dicotomia à pesquisa será muito prejudicada em função da polarização das respostas.

Sobre questões de múltipla escolha, o autor aponta as diversas opções, assim como a agilidade e a objetividade como vantagem, todavia, aponta o cuidado que deve ser levado ao realizar tal tipo de entrevista, uma vez que o entrevistado pode ser influenciado a responder algo em função das respostas pronta apresentadas pelo entrevistador.

As questões levantadas foram aplicadas em ambiente virtual e também com conversas envolvendo professores. A primeira questão abordava qual rede o professor pertencia, as três questões seguintes abordava a relação professor/livro didático, procurando compreender se o professor tinha liberdade para escolher o livro, para tratar de assuntos não abordados pelo livro, e para se aprofundar em assuntos do livro. Já a última abordava a questão da escala de ensino em clima de maneira mais direta.

Segundo dados da Secretaria do Estado de Educação, existem no Paraná, 5.338 professores de geografia na rede pública estadual, sendo que somente em Curitiba são 745 e somando-os com as cidades da região metropolitana chegamos ao valor de 1.248 professores de geografia, o que representa cerca de $23 \%$ de todos os professores da rede pública do estado.

Este valor de 745 professores foi a base para o cálculo da amostragem do número de questionários aplicados. Em função da dificuldade de se obter os números de professores tanto nas escolas privadas quanto nas redes municipais e federais, optou-se por fazer um cálculo probabilístico para se estimar este valor.

Assim, o número de professores de geografia da rede estadual foi dividido pelo número de instituições estaduais de ensino para obter um valor médio de professores por instituição. Para este cálculo o número de alunos por instituição foi generalizado, o que pode disfarçar este número, todavia, a média de professores por instituição não é o dado que se busca, e sim será utilizado para se levantar um número total de professores de geografia na cidade de Curitiba.

A Tabela 1 apresenta o número de instituições em Curitiba conforme a rede a qual pertence:

O número de professores da rede pública estadual dividido pelo número de instituições estaduais nos deu uma média de 5,28 professores por instituição, que, aplicados ao número totalizado de 554 instituições chegamos a um valor estimado de 2.925 professores geografia no município de Curitiba, sendo este o universo de estudo desta pesquisa.

Assim foi calculado o tamanho da amostra a ser feita com base nestes dados e na equação (Eq. 1) apontada por Santos (2014):

$$
\mathrm{n}=\frac{N \cdot Z^{2} \cdot p \cdot(1-p)}{(N-1) \cdot \mathrm{e}^{2}+Z^{2} \cdot p \cdot(1-p)}
$$

A equação leva em conta margem de erro (e), nível de confiabilidade (Z) tamanho do universo a ser 
Tabela 1: Número de instituições de ensino fundamental e/ou médio por rede.

\begin{tabular}{c|c}
\hline REDE & TOTAL \\
\hline Estadual & 141 \\
\hline Privada & 225 \\
\hline Federal & 3 \\
\hline Municipal & 185 \\
\hline Total & $\mathbf{5 5 4}$ \\
\hline
\end{tabular}

Fonte: Secretaria do Estado de Educação - Paraná (2014).

mensurado $(\mathrm{N})$ e heterogeneidade do universo $(\mathrm{p})$ para se chegar ao tamanho da amostra (n).

Assim, foi levantada uma margem de erro de $12 \%$ para a pesquisa, para mais ou para menos. Segundo Triola (1999) "Erro Amostral é a diferença entre um resultado amostral e o verdadeiro resultado populacional; tais erros resultam de flutuações amostrais aleatórias". O autor aponta que a diminuição deste percentual de erro requer uma amostragem maior, o que não foi possível de se realizar em função das limitações logísticas desta pesquisa.

O nível de confiança estipulado foi de $90 \%$, o tamanho do universo de 2.945 pessoas estimadas e uma heterogeneidade do universo de $50 \%$.

A distribuição de Gauss leva em conta o nível de confiança e calcula um índice "Z" a ser utilizado na formula, assim, a um nível de confiança de $90 \%$ estima-se o índice de 1, 645.

Esta proporção " $p$ " (heterogeneidade) aparece na fórmula quando uma população é muito uniforme, convergindo para um mesmo padrão populacional, permitindo reduzir o tamanho da amostra. Se, no entanto, não se tem ideia do tipo de população a ser tratada, a opção mais prudente seria usar o pior cenário: a população se distribui em partes iguais, logo $p=50 \%$ (LEVINE, 2000).

Portanto aplicados estes parâmetros a formula citada, chegou-se ao resultado de quarenta e sete professores como uma amostra adequada amostra esta que representa aproximadamente $1,6 \%$ do universo de análise. Esta pequena quantidade de amostragem se justifica pelo alto nível de erro aplicado à pesquisa.

\section{FUNDAMENTAÇÃO TEORICA}

As diretrizes curriculares do ensino de geografia no estado do Paraná, propostas em 2008, não apresentam especificamente um tema abordando a climatologia, diferentemente de outros estados do país (SOUZA e OLIVEIRA, 2012) todavia a mesma se insere sistemicamente dentro de outros conteúdos a serem ministrados (Tabela 2 ).

A questão climática pode ser abordada, portanto dentro de todos estes temas, todavia, suas definições conforme citadas acima ficam muito superficiais, dando certa liberdade para que o tema possa ser tratado conforme cada livro ou professor preferir.

Ao tratar do conceito de escala, logo nos remetemos à escala cartográfica, o que pode ser considerado muito reducionista em se tratando da amplitude e complexidade de tal conceito dentro da geografia.

A noção de escala em cartografia nos remete a relação entre o espaço analisado dentro de um mapa ou uma carta com o real espaço o qual este representa. Desta maneira, um mapa com uma escala grande representa uma área mais limitada, todavia o nível de detalhes será maior. Já um mapa com uma escala pequena é mais abrangente espacialmente falando, todavia, fatalmente seus detaIhes serão generalizados e simplificados, diminuindo sua carga de informação. Partindo desta explanação, podemos entender a importância de se discutir a escala dentro da geografia. Desta forma observamos uma situação deverás platônica: ou se aumenta a área de estudo e se simplificam os detalhes ou o inverso, diminuímos a área de estudo e aumentamos os detalhes.

Esta discussão não se contenta em manterse nos estudos da geografia, chegando a ser uma questão filosófica por si só, conforme aponta Castro (1992). Sobre esta discussão a autora aponta:

A questão da escala remete tanto é percepção do real nos diversos'tableaux visuels' de Merleau-Ponty, como também ao significado da escolha do conteúdo de cada "tableau". Aqui entramos numa problemática cara às ciências do espaço geografia, arquitetura -e as que estudam os processos físicos e biológicos no espaço. As projeções do real e a realidade contida em cada uma ultrapassam, portanto as possibilidades explicativas e a simplicidade operacional da escala gráfica. A questão que se coloca refere-se ao significado do que se torna visível a uma determinada escala, e o seu significado em relação ao que permanece invisível (também as noções de visível e invisível aqui subsumidas devem ser remetidas a Merleau-Ponty). Neste sentido o que importa é a percepção resultante, na qual o real é presente. A escala é, portanto o artifício visual que dá visibilidade ao real (p.22). 
Tabela 2: Distribuição de conteúdos os quais podemos inserir o ensino de Climatologia de acordo com a DCE do Paraná no ensino Fundamental.

\begin{tabular}{|c|c|}
\hline ANO & CONTEÚDOS \\
\hline \multirow{4}{*}{$6^{\circ}$} & $\begin{array}{l}\text { Formação e transformação das } \\
\text { paisagens naturais e culturais }\end{array}$ \\
\hline & $\begin{array}{c}\text { Dinâmica da natureza e sua alteração } \\
\text { pelo emprego de tecnologias de } \\
\text { exploração e produção }\end{array}$ \\
\hline & $\begin{array}{c}\text { A formação, localização, exploração e } \\
\text { utilização dos recursos naturais }\end{array}$ \\
\hline & $\begin{array}{c}\text { As diversas regionalizações do espaço } \\
\text { geográfico }\end{array}$ \\
\hline \multirow{3}{*}{$7^{o}$} & $\begin{array}{c}\text { A dinâmica da natureza e sua } \\
\text { alteração pelo emprego de } \\
\text { tecnologias de exploração e produção }\end{array}$ \\
\hline & $\begin{array}{c}\text { As diversas regionalizações do espaço } \\
\text { brasileiro }\end{array}$ \\
\hline & $\begin{array}{l}\text { A formação, o crescimento das } \\
\text { cidades, a dinâmica dos espaços } \\
\text { urbanos e a urbanização }\end{array}$ \\
\hline
\end{tabular}

Fonte: organizado pelos autores

Podemos conceituar a escala como a lente individual que aplicamos ao representar e interpretar fenômenos presentes na realidade concreta em que vivemos, e que tem sua concretude mais conhecida e observada dentro da cartografia, mas que também existe em uma série de outras ciências e na nossa própria concepção dos fenômenos, como uma maneira de melhor compreende-los.

Assim, ao se analisar um dado fenômeno espacial podemos utilizar o recurso da escala para aumentá-lo, e assim também sua riqueza de detalhes, ou então diminuí-lo e assim aumentando sua abrangência.

Outro conceito que tentamos trazer para esta discussão é o "lugar". Este conceito tão discutido na geografia contemporânea, em especial pelos geógrafos humanistas já era discutido por La Blache em sua celebre afirmação "A geografia é a ciência dos lugares e não dos homens". De lá para cá foi amplamente discutido e aplicado.
Neste trabalho trataremos do lugar genericamente como espaço vivido, portanto um espaço onde estão contidas percepções, atitudes e valores provenientes dos homens que os habitam.

Santos (1996) esclarece tal conceito e o traz para perto da noção de escala. Segundo o autor (p. 273) "Cada lugar é, ao mesmo tempo, objeto de uma razão global e de uma razão local, convivendo dialeticamente".

Com esta afirmação do autor, observa-se a importância da noção de escala ao se abordar fenômenos espaciais. $\mathrm{O}$ aumento da escala de um fenômeno não faz com que o mesmo deixe de ter sua razão global, da mesma maneira que diminuir sua escala não fará com que o mesmo perca sua razão global.

Agora voltamos à ideia de Piaget (1996) utilizada no início deste trabalho acerca da assimilação, uma etapa fundamental para o processo cognitivo. Segundo o autor, esta é a maneira como um novo dado perceptual ou um conceito é integrado à estrutura cognitiva que o aluno já possui. Ressaltando que tal estrutura provém da realidade vivida pelo aluno e esta deve ser abordada pelo professor.

Reduzir a escala dos fenômenos para a realidade vivida, portanto o lugar, não faz com que os mesmos percam sua razão frente à escala global, e é ferramenta fundamental para a assimilação do conhecimento por parte dos alunos.

\section{RESULTADOS E DISCUSSÃO}

\subsection{Abordagens presentes nos livros didáticos}

Foram observados que os conteúdos os quais a climatologia pode ser inserida estão presentes principalmente no $6^{\circ}$ e $7^{\circ}$ anos do ensino fundamental, definidos assim como objeto desta pesquisa.

Começando pelo livro Espaço e Vivência, observa-se que o livro destaca uma unidade inteira dividida em três capítulos para o ensino de climatologia. Assim primeiramente são explicadas ao aluno, de maneira simples através de quadrinhos e imagens as diferenças entre clima e tempo, além da existência de diferenças entre climas e métodos para medir, tais como estações meteorológicas. 
Saindo desta temática introdutória, o livro passa a apresentar questões mais gerais sobre a natureza do clima. Assim, primeiramente com o auxílio de um mapa é proposta uma discussão sobre os tipos de clima do mundo, seguido por alguns exemplos de variáveis que alteram os climas, como vegetação, relevo, proximidade do mar entre outros.

Em seguida o livro aborda rapidamente as diferenças climáticas no Brasil, trazendo gráficos de diferentes cidades ao longo do país para ilustrar tal diferença, e por fim propõe uma abordagem introdutória sobre a questão das mudanças climáticas, poluição atmosférica, e camada de ozônio.

O outro livro de $6^{\circ}$ ano analisado, Geografia Homem e Espaço, também dá um importante destaque para a climatologia, destacando todo um capitulo para o tema. Assim como no livro anterior, este também inicia sua abordagem com um mapa da classificação de Koppen, passando para uma brevíssima explicação de cada tipo de clima, e suas relações com a vegetação.

Aspectos como o El Niño também são apontados ao longo do capitulo, com uma serie de imagens explicativas cobre o tema. Todavia se limita a isto, aspectos da atmosfera ainda são brevemente tratados em outro capitulo, assim como a diferença entre clima e tempo, todavia não é dada a mesma atenção a temas como clima urbano, poluição atmosférica entre outros.

A fraqueza de detalhes deste livro em relação ao anterior é muito grande, não sendo observados gráficos, tampouco muitas imagens explicativas ou mesmo uma abordagem dos climas do Brasil.

O livro "Geografias do Mundo" para o $7^{\circ}$ ano aborda a questão da urbanização, e rede urbana no Brasil, dentro o qual, está inserida a questão da relação entre urbanização e qualidade do ar, alvo de pesquisa entre muitos geógrafos da climatologia. É apresentada uma série de dados simplificados para os alunos indicando as cidades brasileiras com maiores índices de poluição por material particulado.

Outro aspecto climático tratado no livro aparece no capitulo de nome "Território Brasileiro e a Dinâmica Regional". Neste apartado observamos um trecho explicativo acerca do mapa de Domí- nios Morfoclimáticos Brasileiros feito pelo geógrafo Aziz Ab'Saber. Apresentando uma simples explanação sobre cada um dos domínios apontados pelo autor, além de imagens representativas para auxiliar a assimilação do aluno. Por fim no capitulo intitulado"Biodiversidade e Questão Ambiental no Brasil" são tratados assuntos como mudanças climáticas, buraco na camada de ozônio e desmatamento. Para tanto o livro se utiliza de imagens explicativas e um infográfico didático acerca da composição dos gases que compõe a atmosfera.

Outro livro do $7^{\circ}$ ano, Geografia Espaço e Vivência, aborda logo em seu início os domínios morfoclimáticos do Brasil, seguindo a classificação de Ab'Saber, inclusive utilizando o mesmo mapa do livro anterior, todavia, observamos aqui uma especial ênfase à questão climática na descrição de cada domínio, sendo que, são apresentado junto com imagens de cada domínio, um gráfico representativo de cidades pertencentes ao domínio, contendo, temperaturas e chuvas ao longo do ano, mostrando as diferentes nuances climáticas de cada região brasileira.

A temática da poluição atmosférica e sua relação com a urbanização e industrialização também foi abordado no capitulo intitulado "O espaço urbano brasileiro", todavia o assunto é tratado de maneira muito breve. Em seguida, o livro parte para uma abordagem regional do Brasil. No capítulo referente a região nordeste, a questão do regime de chuvas, e relação com o relevo é muito bem tratada, utilizando-se de imagens e infográficos, onde inclusive se propõe uma comparação entre o regime de chuvas de cidades do sertão nordestino com cidades do deserto chileno.

No capítulo referente a região sul, o clima volta a ser abordado no que diz respeito ao seu aspecto urbano, dando especial ênfase as enchentes nas grandes cidades da região como Belo Horizonte e São Paulo.

No capítulo referente à região tratada, o regime de chuvas da região amazônica é especialmente tratado, sendo devidamente explicada como se dão estes processos, e sua relação com a vegetação. O clima do Sul também foi abordado sendo desta vez relacionado com a agricultura. As- 
sim, o clima majoritariamente temperado foi comparado com as No capítulo referente a região sul, o clima volta a ser abordado no que diz respeito ao seu aspecto urbano, dando especial ênfase as enchentes nas grandes cidades da região como Belo Horizonte e São Paulo.

No capítulo referente a região tratada, o regime de chuvas da região amazônica é especialmente tratado, sendo devidamente explicada como se dão estes processos, e sua relação com a vegetação. O clima do sul também foi abordado sendo desta vez relacionado com a agricultura. Assim, o clima majoritariamente temperado foi comparado com as culturas da região. A região centro -oeste foi a única onde a questão climática não foi abordada pelo livro.

Por fim o último livro analisado, Projeto Araribá, apresenta de início, a localização do Brasil dentre as grandes zonas térmicas da Terra. Em seguida, tratando de processos urbanizatórios, trata de maneira pobre a questão da poluição atmosférica nos grandes centros, deixando aspectos como a enchente de fora.

Entrando na regionalização do Brasil, o livro se inicia com a região norte, e dedica mais afinco a questão climática do local, em especial aos altos índices de chuva, trazendo um mapa de precipitação e outro de temperatura.

Assim segue na região nordeste, onde a questão da seca é tratada com mais aprofundamento, destacando-se que algumas áreas especificas do nordeste sofrem com seca e não a região como um todo.

As regiões sul e sudeste têm seus climas pobremente descritos e trabalhados, somente com o advento de textos, sem a presença de mapas ou imagens explicativas. $\mathrm{O}$ mesmo não ocorre com a região centro-oeste, última a ser abordada, que apresenta uma descrição mais detalhada de seus aspectos climáticos, contando com mapas de temperatura e precipitação.

O que se observou nas análises acima feitas foram abordagens generalizadas da climatologia no ensino de geografia inseridas como partes de outros conteúdos. A aproximação maior que observamos foi no âmbito municipal. Tal analise, cor- robora com a ideia de que, se o professor depender exclusivamente do livro didático o conteúdo de climatologia será apresentado de maneira deficitária.

Esta "distância" observada nos livros didáticos e consequentemente nas aulas interfere na capacidade do aluno de assimilar a climatologia enquanto parte de seu aprendizado. Uma das possibilidades para sanar tal dificuldade é a proposta de Carvalho e Filizola (2005) de desenvolvimento do raciocínio escalar.

Segundo os autores:

[...] raciocínio escalar que permite que a criança pos-
sa estabelecer relações de proporção e entender o que
acontece com os fenômenos geográficos nas diferentes
escalas dos lugares e do território (igarapé, vila, rio, re-
gião, morro, país, cidade, arroio, continente, planeta, ilha,
laguna, cidade, praia, distrito, bairro, etc.) (p. 30).

O desenvolvimento de um raciocínio escalar enquanto parte de um raciocínio geográfico (FILIZOLA, 2005), permite que o educando estabeleça a noção de localização, distância e magnitude e assim assimile fenômenos geográficos dentre os quais trataremos os relacionados ao clima.

A aplicação de raciocínio escalar no ensino de climatologia, a qual chamaremos de climatologia escalar se baseia em métodos os quais permitem que o educando assimile os fenômenos de climatologia e então possa expandi-los, compreendendo em seguida a distribuição de tais no espaço.

Alguns destes métodos, já são amplamente explorados ou já foram propostos dentro da academia. Venturini (2004 apud SOUZA, 2012) Vasconcelos (2012), Rezende et al. (2012) dentre outros, propõe a confecção de equipamentos de medições meteorológicas simples como ferramenta de auxílio ao ensino. Instrumentos estes feitos de materiais simples como garrafas PET. Não só a confecção de tais equipamentos, mas principalmente, o monitoramento de fenômenos através destes se configura como um método chave.

Através de tal monitoramento, podem-se realizar comparações entre os fenômenos ocorridos ao longo de um ano, ou de um mês, propondo que o educando assimile a magnitude dos mesmos. Em conjunto a tal ideia, pode-se realizar uma saída a campo visando mostrar ao 
aluno na pratica a consequência deste evento, por exemplo, em um córrego próximo, ou mesmo através de imagens ou vídeos.

A questão físico-química da climatologia também pode ser abordada dentro deste contexto com a utilização de modelos rústicos de mensuração de material particulado em suspensão, MPS como o proposto por Santos (2011). Tal método se utiliza de filtros de café convencionais e pesagens para atingir parâmetros de tal poluente.

A utilização da realidade do aluno como objeto de estudo, e consequentemente de ensino, é outra estratégia do desenvolvimento desta climatologia escalar em sala de aula. Uma atividade proposta, neste caso seria necessária a interação entre escolas, seria a medição conjunta, por exemplo, da temperatura, em escolas localizadas em locais diferentes, o que permitiria aos alunos compreenderam a questão das ilhas de calor em grandes cidades. O mesmo pode ser feito com o método para medição de MPS. E assim subsequentemente, se elevando a escala do fenômeno.

Esta discussão foi levada ao XI Simpósio Brasileiro de Climatologia Geográfica, ocorrido no mês de outubro em Curitiba, e foram tratadas no eixo "Ensino de Climatologia".

Tal debate correu ao ponto em que se concluiu que o professor não pode e não deve ser refém do livro didático, e que não há como o próprio livro abordar escalas locais do ensino, uma vez que, o mesmo é produzido de maneira geral para o Brasil todo, cabendo ao professor o papel de fazer tal aproximação.

\subsection{Resultados dos questionários}

A fim de se levantar a real relação entre professor e livro didático foi aplicado um questionário segundo parâmetros previamente citados com professores das redes pública e privada dos ensinos médio e fundamental na cidade de Curitiba.

Dos entrevistados, a grande maioria pertencia a rede pública estadual, totalizando $72,34 \%$ dos entrevistados, seguido pela rede privada, municipal e federal (Figura 1).

A pergunta seguinte apontava sobre a liberdade do professor para escolher ou debater sobre a escolha do livro didático, sendo que a maioria, $82,98 \%$, possui tal liberdade. Outros $14,89 \%$, responderam que não possuem tal liberdade, e somente $2,13 \%$ citaram que sua escola não possui livro didático (Figura 2).

Interessante fazer outra analise desta pesquisa separando os resultados por tipo de rede de ensino. Assim observa-se que em todas as redes a maioria dos professores tem esta liberdade, todavia este valor cai ao se aplicar esta lente apenas nos professores da rede privada e chegam a totalidade ao ser aplicada as do ensino municipal (Figura 3).

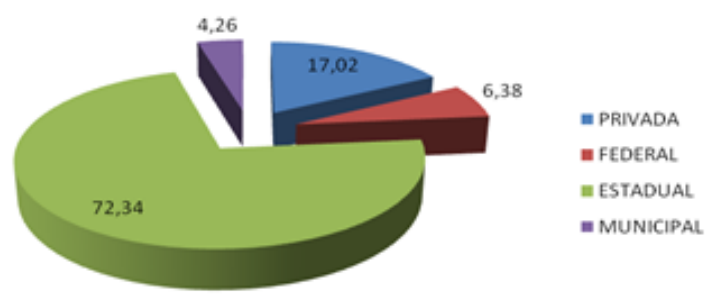

Figura 1: Respostas concernentes à pergunta 1:"A rede o qual você ensina pertence a qual rede?" Fonte: elaborado pelos autores.

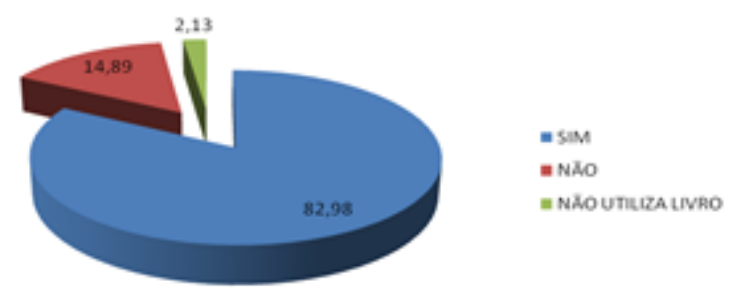

Figura 2: Respostas concernentes a pergunta 2: "O local onde você é professor lhe dá liberdade para escolher ou discutir a escolha do livro didático a ser utilizado no ano letivo?" Fonte: elaborado pelos autores.

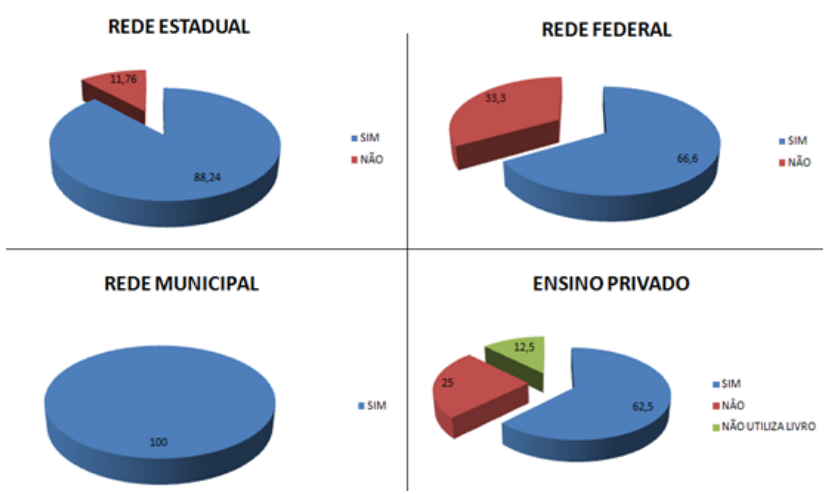

Figura 3: Respostas concernentes a pergunta 2: “O local onde você é professor lhe dá liberdade para escolher ou discutir a escolha do livro didático a ser utilizado no ano letivo?" separado conforme rede de ensino. Fonte: elaborado pelos autores. 
Em seguida ao serem questionados sobre a liberdade para tratar de assuntos não presentes no livro, a grande maioria, 93,62\%, respondeu que sim, possui tal liberdade, enquanto que apenas $6,38 \%$ responderam negativamente (Figura 4).

Novamente, ao serem questionados sobre a liberdade em se aprofundar em questões tratadas no livro à ampla maioria respondeu positivamente, totalizando $93,62 \%$ dos entrevistados, enquanto que somente $6,38 \%$ responderam de maneira negativa (Figura 5).

Por fim a última questão foi a que se mostrou com maior heterogeneidade de resultados. Acerca da escala trabalhada em sala de aula, a maior parte respondeu tratar da climatologia e seus fenômenos em escala estadual, totalizando $34,04 \%$ das respostas, em seguida temos a escala nacional com $29,79 \%$, seguido por global com $17,02 \%$ e municipal com $6,38 \%$, por fim local com 10,64\% sendo a menos citada (Figura 6). Importante citar que não foram notadas diferenças expressivas entre os tipos de rede o qual o professor faz parte (Figura 7). Embora pode-se perceber que tanto o ensino em rede federal quanto o ensino em rede privada tenham apresentado os maiores percentuais na escala local.

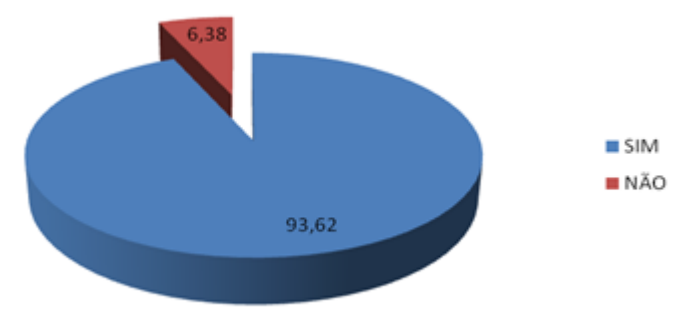

Figura 4: Respostas concernentes a pergunta 3:"Você possui liber-dade para tratar de questões NÃO abordadas pelo livro?" Fonte: elaborado pelos autores.

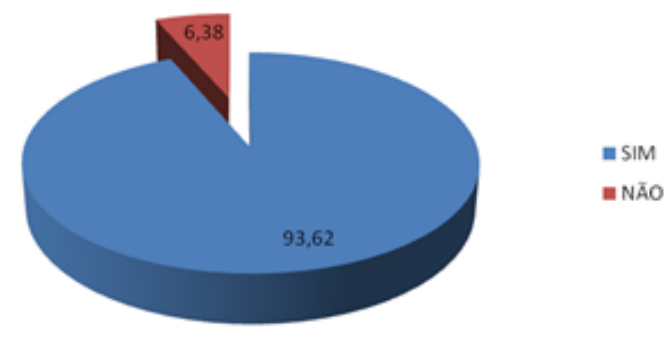

Figura 5: Respostas concernentes a pergunta 4: "Você possui liberdade para se aprofundar em temas tratados pelo livro didático?" Fonte: elaborado pelos autores.

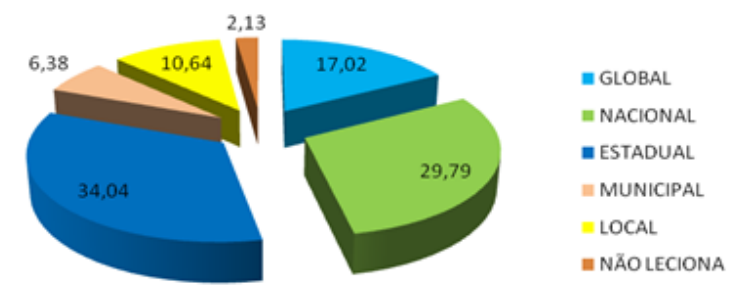

Figura 6: Respostas concernentes a pergunta 5: “Em se tratando do ensino de Climatologia em especifico, este tema é abordado em até qual escala dentro da disciplina de geografia? Global, Nacional,

Estadual, municipal ou local (bairro ou entorno da escola)?" Fonte: elaborado pelos autores.

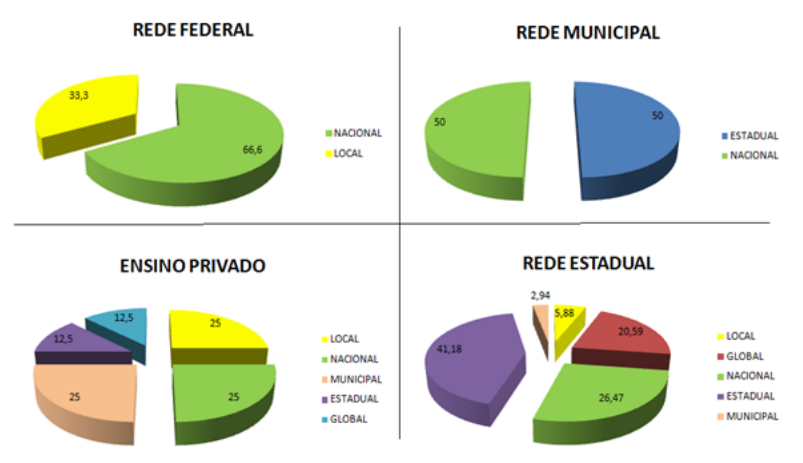

Figura 7: Respostas concernentes a pergunta 5: “Em se tratando do ensino de Climatologia em especifico, este tema é abordado em até qual escala dentro da disciplina de geografia? Global, Nacional, Estadual, municipal ou local (bairro ou entorno da escola)?" divididos entre as redes de ensino.

Fonte: elaborado pelos autores.

\section{CONCLUSÃO}

O ensino de climatologia se mostrou como possuindo uma grande lacuna, e adquirindo em certos casos um caráter enciclopédico dentro dos livros didáticos. De que lacuna se está falando? Dificilmente encontramos alguém, (fora da geografia) que tenha noção de fenômenos climatológicos. Um exemplo simples para questionar-se: Um evento de precipitação de $25 \mathrm{~mm}$ em 24 horas é considerado como de grande ou baixa magnitude? Ou ainda, um local especifico que tenha como temperatura média anual $20^{\circ} \mathrm{C}$ é considerado quente ou frio?

Tais questionamentos dificilmente serão respondidos satisfatoriamente, apesar de serem fenômenos correntes no cotidiano de qualquer cidadão, independente de classe social, ou local onde vivem. Como podemos ensinar uma climatologia generalizada se tais conceitos chave para a assimilação deste conteúdo não são devidamente 
tratados no ambiente escolar?

Há de se lembrar que as aulas nem sempre são inteiramente baseadas nos conteúdos propostos pelos livros didáticos, mas muitas vezes, acabam por ser o único recurso de professores que não tem o devido preparo, ou mesmo, interesse, isso foi comprovado com a pesquisa feita ao longo do trabalho, em que $82,98 \%$ dos entrevistados afirmaram ter liberdade para escolher os livros, 93,62\% afirmaram poder tratar de assuntos não presentes no livro e por fim 93,62\% afirmaram ter liberdade para se aprofundar em questões abordadas do livro.

Assim foram propostos métodos que desenvolvam este raciocino escalar dentro da temática da climatologia, utilizando o conceito de lugar como base para tal evolução cognitiva.

Foi constatado que a escala local, esta que abrange o "lugar" foi a menos citada pelos professores, o que mostra a real necessidade destes serem revistos, uma vez que, conforme citado anteriormente, a grande maioria dos professores possui esta liberdade para dar outras abordagens em relação a proposta pelos livros didáticos.

A construção do conhecimento climatológico através destes métodos facilita a continuidade do ensino para temas mais gerais no âmbito da climatologia. A partir do momento em que o educando compreende tais fenômenos elevá-los a outras escalas se torna mais fácil para o professor e para o aluno.

De acordo com o DCE, o professor possui liberdade para tratar dos temas em sala de aula na escala que desejar, o que de fato foi constatado por este estudo.

A escolha da escala de estudo, na grande maioria dos casos é pessoal do professor, tendo em vista que dentre os entrevistados, somente $6,38 \%$ alegaram não ter liberdade para tratar de assuntos fora do livro e outros 6,38\% não ter liberdade para se aprofundar em assuntos do livro.

Analisando os livros, observa-se que de fato, a escala adotada por estes é sempre muito ampla, portanto cabe ao professor fazer esta aproximação, facilitando o processo de assimilação.

Outro ponto observado é que, de fato, poucos são os professores que fazem tal aproximação, somente $10,64 \%$ alegou tratar de assuntos relacio- nados a clima na escala local.

Deve-se levar em conta quê esta pesquisa contou com um número limitado de entrevistados o que aumentou a margem de erro e diminuiu seu nível de confiança, índices estes que fazem com que, os valores aqui apresentados tenham ampla margem de discussão, embora possam ser aceitos.

Todavia, apesar destes dados, não podemos culpar o professor pela baixa escala utilizada. Em conversas informais com os entrevistados muitos relataram um calendário muito apertado e pouco tempo hábil para de fato realizar esta aproximação, reconhecendo sua importância.

O tempo de aulas destinado ao curso de geografia é pouco se comparado com outras disciplinas como língua portuguesa e matemática, fato este já muito discutido, e que limita a atuação do professor de geografia dentro de sala de aula.

A contemporaneidade da questão ambiental na sociedade moderna eleva a importância de tais estudos em ambiente escolar, e tal fato deveria ser tratado entre outras disciplinas, majoritariamente na geografia escolar, o que elevaria sua importância dentro das escolas.

Neste ponto observamos o aumento na escala conforme proposto por Carvalho (2006) como parte de um desenvolvimento do raciocínio escalar do aluno, o que conforme citado anteriormente facilita o processo de assimilação dos fenômenos espaciais, dentre estes, sociais e ambientais, sendo este o real objetivo da geografia escolar.

\section{REFERÊNCIAS BIBLIOGRÁFICAS}

AAKER, D. A.; KUMAR, V.; LEONE, R.; DAY, G. S. Marketing Research, New York: John Wiley \& Sons Inc, 2001.

ALVES, A.; MARTINEZ, R.; VIDAL, W.; BOLIGIAN L. Geografia - Espaço e Vivência - $6^{\circ}$ Ano, São Paulo: Editoria Atual, 2009.

ALVES, A.; MARTINEZ, R.; VIDAL, W.; BOLIGIAN L. Geografia - Espaço e Vivência - 7० Ano, São Paulo: Editoria Atual, 2009.

BRANCO, A. L.; LUCCI, E. A. Geografia - Homem \& Espa- 
ço- 6a Ano - 5a Série, 22ª ed., São Paulo: Saraiva, 2010.

CASTELHANO,F. J. Raciocínio Escalar em Climatologia: Abordagens Teóricas, XI SIMPÓSIO BRASILEIRO DE CLIMATOLOGIA GEOGRÁFICA, Anais... Curitiba, 2014.

CASTRO, I. E. Analise Geográfica e o Problema Epistemológico da Escala, Anuário do Instituto de Geociências, v.15, Rio de Janeiro, p. 21-25, 1992.

CARVALHO, A. L. P.; FILIZOLA, R. A avaliação em Geografia nas séries Iniciais. Curitiba: Ed. UFPR, 2005.

CARVALHO, A. L. P. Cadernos Pedagógicos de Geografia, Curitiba: Ed. da UFPR, 2006.

FILIZOLA, R. Metodologia do Ensino de Geografia: considerações teórico-metodológicas, SIMPÓSIO DE EDUCAÇÃO PROFISSIONAL DO CURSO DE FORMAÇÃO DE DOCENTES, Anais... Faxinal do Céu, 2005.

HOLZER, W. O lugar na geografia humanista, Revista Território, ano IV, n. 7, p. 67-78, Rio de Janeiro, 1999.

LEVINE, D. M.; BERENSON, M. L.; STEPHAN, D. Estatística: Teoria e Aplicações usando Microsoft Excel em Português. Rio de Janeiro: LTC, 2000.

MATTAR, F. N. Pesquisa de marketing: metodologia, planejamento, execução e análise, $2^{a}$ ed. São Paulo: Atlas, v. 2, 1994.

PEREIRA, D. A. C.; CARVALHO, M. B. de. Geografias do Mundo - 6a Série/7 Ano, São Paulo: FTD, 2009.

PIAGET, J. Biologia e Conhecimento. Petrópolis: Vozes, 1996.

SANTOS, V. A.; SILVA, C. A. O clima de Dourados (MS) e a proposição de um roteiro-metodológico simples para entender a poluição atmosférica de áreas, In: ANAIS DO $2^{\circ}$ ENCONTRO DE ENSINO DE GRADUAÇÃO; $4^{\circ}$ ENCONTRO DE PÓS-GRADUAÇÃO; $5^{\circ}$ ENCONTRO DE INICIAÇÃO CIENTIFICA 5० ENCONTRO DE EXTENSÃO Anais... Dourados, 2011.

SANTOS, G. E. de O. Cálculo amostral: calculadora on-line. Disponível em: <http://www.calculoamostral.vai. la>. Acesso em: 11/11/2014.
SANTOS, M. A natureza do espaço: técnica e tempo, razão e emoção. São Paulo: HUCITEC, 1996.

SOUZA, M. I. A.; OLIVEIRA, A. O. S. A. A alfabetização climatológica: Análise dos conteúdos de climatologia nos livros didáticos e preposição de novas estratégias para o ensino de clima, Revista Geonorte, ed. especial 2, v.1, n.5, p. 22-33, 2012.

REZENDE, D. F; MARIANO, Z. F.; AGUIAR, R. C. de P.; CARVALHO, L. F. M. O Uso de materiais didáticos no ensino de climatologia, Revista Geonorte, ed. especial 2, v.1, n.5, p. 207-217, 2012.

RUA, J. A Natureza. In: Para aprender Geografia - Contribuição para o trabalho com 1 e 2 graus. Rio de Janeiro: Access, 1993.

TUAN,Y. F. Place: an experiential perspective. The Geographical Review, 65 (2), p. 151-165, 1975.

TRIOLA, Mário F. Introdução à Estatística. 7a. Ed. Rio de Janeiro: LTC, 1999.

VASCONCELOS, L. C. da S. A construção de instrumentos meteorológicos como pratica didática da climatologia no ensino fundamental, Revista Geonorte, ed. especial 2, v.1, n.5, p. 34-45, 2012.

VEDOVAlTA F. C. Projeto Araribá - Geografia/ 70 ano, São Paulo: Moderna, 2010.

Correspondência dos autores:

Francisco Jablinski Castelhano e-mail: francisco_castelhano@hotmail.com

Wilson Flavio Feltrim Roseghini e-mail: feltrim@gmail.com

Artigo recebido em: 11/02/2014

Revisado pelos autores em: 27/09/2015

Aceito para publicação em: 25/10/2015 